Louisiana State University

LSU Digital Commons

Faculty Publications

Department of Chemistry

$12-11-2012$

\title{
Aggregation and dynamics of oligocholate transporters in phospholipid bilayers revealed by solid-state NMR spectroscopy
}

\author{
Tuo Wang \\ lowa State University \\ Lakmini Widanapathirana \\ lowa State University \\ Yan Zhao \\ lowa State University \\ Mei Hong \\ lowa State University
}

Follow this and additional works at: https://digitalcommons.Isu.edu/chemistry_pubs

\section{Recommended Citation}

Wang, T., Widanapathirana, L., Zhao, Y., \& Hong, M. (2012). Aggregation and dynamics of oligocholate transporters in phospholipid bilayers revealed by solid-state NMR spectroscopy. Langmuir, 28 (49), 17071-17078. https://doi.org/10.1021/la303661p

This Article is brought to you for free and open access by the Department of Chemistry at LSU Digital Commons. It has been accepted for inclusion in Faculty Publications by an authorized administrator of LSU Digital Commons.

For more information, please contact ir@lsu.edu. 


\section{IOWA STATE UNIVERSITY \\ Digital Repository}

$11-2012$

\section{Aggregation and Dynamics of Oligocholate Transporters in Phospholipid Bilayers Revealed by Solid-State NMR Spectroscopy}

Tuo Wang

Iowa State University

Lakmini Sandachaya Widanapathirana

Iowa State University

Yan Zhao

Iowa State University, zhaoy@iastate.edu

Follow this and additional works at: http://lib.dr.iastate.edu/chem_pubs

Part of the Chemistry Commons

The complete bibliographic information for this item can be found at http://lib.dr.iastate.edu/ chem_pubs/185. For information on how to cite this item, please visit http://lib.dr.iastate.edu/ howtocite.html.

This Article is brought to you for free and open access by the Chemistry at Iowa State University Digital Repository. It has been accepted for inclusion in Chemistry Publications by an authorized administrator of Iowa State University Digital Repository. For more information, please contact digirep@iastate.edu. 


\title{
Aggregation and Dynamics of Oligocholate Transporters in Phospholipid Bilayers Revealed by Solid-State NMR Spectroscopy
}

\begin{abstract}
Macrocycles made of cholate building blocks were previously found to transport glucose readily across lipid bilayers. In this study, an $15 \mathrm{~N}, 13 \mathrm{C} \alpha$-labeled glycine was inserted into a cyclic cholate trimer and attached at the end of a linear trimer, respectively. The isotopic labeling allowed us to use solid-state NMR spectroscopy to study the dynamics, aggregation, and depth of insertion of these compounds in lipid membranes. The cyclic compound was found to be mostly immobilized in DLPC, POPC/POPG, and POPC/POPG/cholesterol membranes, whereas the linear trimer displayed large-amplitude motion that depended on the membrane thickness and viscosity. 13C-detected $1 \mathrm{H}$ spin diffusion experiments revealed the depth of insertion of the compounds in the membranes, as well as their contact with water molecules. The data support a consistent stacking model for the cholate macrocycles in lipid membranes, driven by the hydrophobic interactions of the water molecules in the interior of the macrocycles. The study also shows a strong preference of the linear trimer for the membrane surface, consistent with its lack of transport activity in earlier liposome leakage assays.
\end{abstract}

\section{Disciplines}

Chemistry

\section{Comments}

Reprinted (adapted) with permission from Langmuir 28 (2012): doi:10.1021/la303661p. Copyright 2012 American Chemical Society. 


\title{
Aggregation and Dynamics of Oligocholate Transporters in Phospholipid Bilayers Revealed by Solid-State NMR Spectroscopy
}

\author{
Tuo Wang, Lakmini Widanapathirana, Yan Zhao,* and Mei Hong* \\ Department of Chemistry, Iowa State University, Ames, Iowa 50011-3111, United States
}

\begin{abstract}
Macrocycles made of cholate building blocks were previously found to transport glucose readily across lipid bilayers. In this study, an ${ }^{15} \mathrm{~N},{ }^{13} \mathrm{C} \alpha$-labeled glycine was inserted into a cyclic cholate trimer and attached at the end of a linear trimer, respectively. The isotopic labeling allowed us to use solid-state NMR spectroscopy to study the dynamics, aggregation, and depth of insertion of these compounds in lipid membranes. The cyclic compound was found to be mostly immobilized in DLPC, POPC/POPG, and POPC/POPG/cholesterol membranes, whereas the linear trimer displayed large-amplitude motion

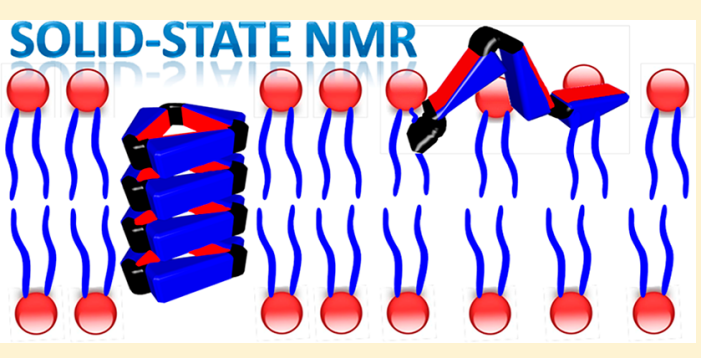
that depended on the membrane thickness and viscosity. ${ }^{13} \mathrm{C}$-detected ${ }^{1} \mathrm{H}$ spin diffusion experiments revealed the depth of insertion of the compounds in the membranes, as well as their contact with water molecules. The data support a consistent stacking model for the cholate macrocycles in lipid membranes, driven by the hydrophobic interactions of the water molecules in the interior of the macrocycles. The study also shows a strong preference of the linear trimer for the membrane surface, consistent with its lack of transport activity in earlier liposome leakage assays.
\end{abstract}

\section{INTRODUCTION}

Membrane proteins perform vital biological functions including photosynthesis, ion conduction, signal transduction, and immune response and, not surprisingly, account for nearly $50 \%$ of all drug targets. ${ }^{1,2}$ Protein-based pores and channels are frequently used by cells to control the traffic across their membranes. ${ }^{3-5}$ Structural characterization of these proteins is essential to a detailed understanding of molecular transport across lipid membranes but is hampered by the difficulty in expressing and crystallizing membrane proteins in general. The characterization sometimes is difficult also because the structure of the active transporter may vary with lipid composition and the presence of other proteins or ligands.

Chemists can contribute to the understanding of membrane transport from a different perspective. By studying synthetic pore-forming materials, they develop a fundamental understanding of the self-assembling mechanism involved in pore formation. ${ }^{6-12}$ Because similar covalent and noncovalent forces are involved in both biological and synthetic nanopores, learning from one can shed light on the other. In addition, structureactivity correlation is more straightforward in simpler synthetic pores, making it easier to extract the fundamental principles that might operate in both systems. Furthermore, synthetic pores, especially those opened and closed (i.e., gated) by chemical or physical stimuli, have practical applications such as delivery of hydrophilic molecules across cell membranes, ${ }^{8-12}$ sensing, ${ }^{13}$ DNA sequencing, ${ }^{14-19}$ and catalysis. ${ }^{20}$

Recently, we extended the solvophobic folding of linear oligocholate foldamers in organic solution to the membrane environment and created synthetic nanopores formed by oligocholate macrocycles. ${ }^{21,22}$ The driving force for these nanopores differs significantly from those in reported synthetic nanopores that typically rely on hydrogen bonds, ${ }^{20,23-25}$ aromatic interactions, ${ }^{26,27}$ or metal-ligand coordination ${ }^{28,29}$ for assembly. Amphiphilic macrocycles such as 1 and $\mathbf{2}$ have a highly polar interior that tends to carry a pocket of water. When the molecules enter a lipid bilayer, the internal water molecules serve to solvate the polar amide and hydroxyl groups in the nonpolar membrane. For a nonaggregated macrocycle, however, these water molecules are exposed to hydrocarbon on one side of the macrocycle if the molecule lies near the membrane surface and on both sides if it penetrates into the membrane (Figure 1). Such unfavorable hydrophilic-hydrophobic contact can be minimized if multiple macrocycles stack over one another to form a transmembrane (TM) pore. The arrangement allows the water molecules inside the macrocycles to solvate the polar groups of the cholates and still exchange with the bulk water readily. The solvent exchange is entropically favorable to the pore formation. Indeed, it is known that, in some cases, the (entropic) cost for trapping a single water molecule can be as high as $2 \mathrm{kcal} /$ mol. $^{30}$

The main support for the hydrophobically driven pore formation so far was from leakage assays. ${ }^{21,22}$ Spectroscopic evidence was also obtained from the excimer emission of pyrenelabeled macrocycles such as $4^{21,31}$ More recently, we took advantage of the environmental sensitivity of the dansyl group and studied compounds 5 and 6 by a number of fluorescence techniques. The study yielded significant insight into the relationship between the amphiphile topology and its aggregation in the membrane environment. ${ }^{32}$

Solid-state NMR spectroscopy is a powerful technique to study structure, dynamics, and topology of membrane-bound

Received: September 11, 2012

Revised: November 12, 2012

Published: November 15, 2012 

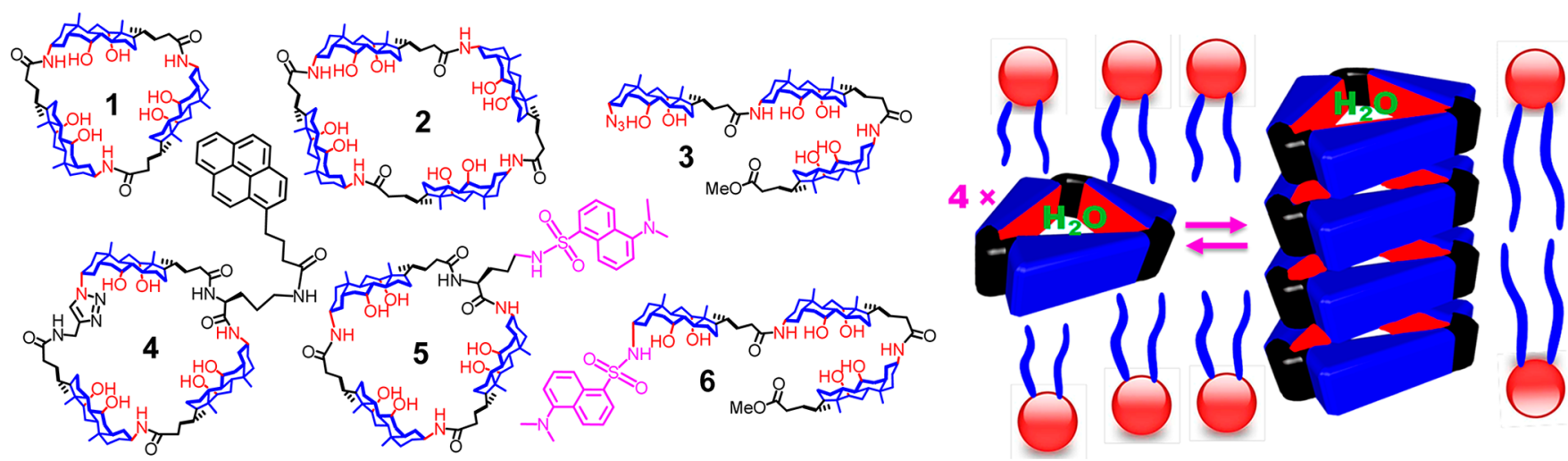

Figure 1. Structures of cyclic and linear oligocholates and the idealized transmembrane pore from stacked oligocholate macrocycles in a lipid bilayer membrane.

proteins and other macromolecules. ${ }^{33,34}{ }^{13} \mathrm{C}$ and ${ }^{15} \mathrm{~N}$ chemical shifts give information about the conformation of the membranebound species while lipid-protein interactions can be investigated by using various 2D correlation NMR experiments. In particular, ${ }^{1} \mathrm{H}$ spin diffusion from lipid acyl chains or water to the macromolecule of interest can afford semiquantitative information about the depth of insertion and water proximity of the macromolecules, respectively. ${ }^{35,36}$

In this paper, we prepared a cyclic trimer (7) and a linear trimer (8) containing an ${ }^{15} \mathrm{~N},{ }^{13} \mathrm{C} \alpha$-labeled glycine unit. These compounds are referred to as the cyclic trimer (CT) and linear trimer (LT), respectively. The isotope label allowed us to measure the dynamics, aggregation, and depth of insertion of these oligocholates in lipid membranes using solid-state NMR spectroscopy. Previously, incorporation of a single $\alpha$-amino acid residue in the oligocholate macrocycle was found to be welltolerated by the pore formation. ${ }^{31}$ In comparison to 5 and $\mathbf{6}$, the glycine-containing compounds represent better models for the parent compounds (i.e., 1 and 3 ), due to the small size of the label.
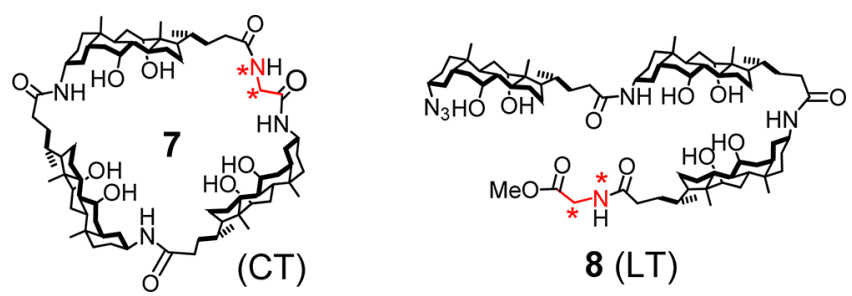

\section{EXPERIMENTAL SECTION}

Synthesis of Compound 8 (LT). The carboxylic acid derivative of 3 (150 mg, $0.122 \mathrm{mmol})$, glycine methyl ester hydrochloride $(31 \mathrm{mg}$, $0.244 \mathrm{mmol}$ ), benzotriazole-1-yl-oxy-tris(dimethylamino)phosphonium hexafluorophosphate (BOP, $135 \mathrm{mg}, 0.305 \mathrm{mmol}$ ), and 1-hydroxybenzotriazole ( $\mathrm{HOBt}, 42 \mathrm{mg}, 0.305 \mathrm{mmol}$ ) were dissolved in DMF $(0.5 \mathrm{~mL})$, followed by the addition of $\mathrm{N}, \mathrm{N}$-diisopropylethylamine (DIPEA, $0.17 \mathrm{~mL}, 0.976 \mathrm{mmol}$ ). The mixture was allowed to react in a microwave reactor at $100{ }^{\circ} \mathrm{C}$ for $45 \mathrm{~min}$ and poured into dilute $\mathrm{HCl}$ aqueous solution $(0.05 \mathrm{M}, 200 \mathrm{~mL})$. The precipitate formed was collected by suction filtration, washed with water, dried in air, and purified by column chromatography over silica gel with $8: 1 \mathrm{CH}_{2} \mathrm{Cl}_{2} /$ $\mathrm{CH}_{3} \mathrm{OH}$ as the eluent to afford an ivory powder $(140 \mathrm{mg}, 89 \%) .{ }^{1} \mathrm{H}$ NMR (400 MHz, CD 30 OD/CDCl $1: 1) \delta 4.09(\mathrm{~s}, 1 \mathrm{H}), 3.94(\mathrm{br}, 3 \mathrm{H})$, $3.79(\mathrm{br}, 3 \mathrm{H}), 3.74(\mathrm{~s}, 1 \mathrm{H}), 3.71(\mathrm{~s}, 3 \mathrm{H}), 3.53(\mathrm{~m}, 2 \mathrm{H}), 3.16(\mathrm{~m}, 1 \mathrm{H})$, 2.36-0.93 (a series of m), $0.90(\mathrm{~s}, 9 \mathrm{H}), 0.68(\mathrm{~m}, 9 \mathrm{H}) .{ }^{13} \mathrm{C}$ NMR $(100$ $\left.\mathrm{MHz}, \mathrm{CDCl}_{3} / \mathrm{CD}_{3} \mathrm{OD}=1: 1\right) \delta 175.8,174.0,170.4,73.0,68.0,61.7$,
$49.8,47.1,46.5,42.3,41.8,41.1,40.9,39.7,36.4,36.1,35.7,35.6,35.0$, 34.7, 33.5, 33.0, 23.2, 22.6, 17.1, 12.1. ESI-HRMS $(m / z):[\mathrm{M}+\mathrm{H}]^{+}$ calcd for $\mathrm{C}_{74}\left[{ }^{13} \mathrm{C}\right] \mathrm{H}_{123} \mathrm{~N}_{5}\left[{ }^{15} \mathrm{~N}\right] \mathrm{O}_{11} 1285.9248$, found 1285.9217 .

Synthesis of Compound 7 (CT). Compound 8 (100 mg, 0.078 $\mathrm{mmol})$ and triphenylphosphine $(31 \mathrm{mg}, 0.117 \mathrm{mmol})$ were dissolved in $\mathrm{MeOH}(10 \mathrm{~mL})$. The reaction mixture was heated to reflux overnight. The solvent was removed by rotary evaporation. The residue was purified by column chromatography over silica gel with $15: 1 \mathrm{CH}_{2} \mathrm{Cl}_{2}$ / $\mathrm{CH}_{3} \mathrm{OH}$ and 6:1:0.1 $\mathrm{CH}_{2} \mathrm{Cl}_{2} / \mathrm{CH}_{3} \mathrm{OH} / \mathrm{Et}_{3} \mathrm{~N}$ as the eluents to afford an off-white powder $(95 \mathrm{mg}, 97 \%)$. This product was dissolved in $\mathrm{MeOH}$ $(3 \mathrm{~mL})$ and a solution of $2 \mathrm{M} \mathrm{LiOH}(0.4 \mathrm{~mL}, 0.754 \mathrm{mmol})$ was added. The reaction was stirred at room temperature and monitored by TLC. After the hydrolysis was complete, the organic solvent was removed by rotary evaporation. After addition of a dilute $\mathrm{HCl}$ solution $(30 \mathrm{~mL}, 0.05$ $\mathrm{M})$, the precipitate formed was collected by centrifugation, washed with cold water, and dried in vacuo. A portion of the hydrolyzed compound $(50 \mathrm{mg}, 0.040 \mathrm{mmol}), \mathrm{BOP}(89 \mathrm{mg}, 0.201 \mathrm{mmol})$, and HOBT $(27 \mathrm{mg}$, $0.201 \mathrm{mmol}$ ) were dissolved in DMF $(40 \mathrm{~mL})$, followed by the addition of DIPEA $(56 \mu \mathrm{L}, 0.321 \mathrm{mmol})$. The mixture was allowed to react in a microwave reactor at $100^{\circ} \mathrm{C}$ for $1 \mathrm{~h}$ and poured into dilute $\mathrm{HCl}$ aqueous solution $(0.05 \mathrm{M}, 100 \mathrm{~mL})$. The precipitate formed was collected by suction filtration, washed with water, dried in air, and purified by column chromatography over silica gel with $10: 1 \mathrm{CH}_{2} \mathrm{Cl}_{2} / \mathrm{CH}_{3} \mathrm{OH}$ as the eluent to afford an ivory powder $(43 \mathrm{mg}, 86 \%) .{ }^{1} \mathrm{H}$ NMR $\left(400 \mathrm{MHz}, \mathrm{CD}_{3} \mathrm{OD} /\right.$ $\left.\mathrm{CDCl}_{3} 1: 1\right) \delta 3.94(\mathrm{br}, 3 \mathrm{H}), 3.79(\mathrm{br}, 3 \mathrm{H}), 3.51(\mathrm{~m}, 4 \mathrm{H}), 3.36(\mathrm{~s}, 2 \mathrm{H})$, $3.15(\mathrm{~m}, 1 \mathrm{H}), 2.34-0.80($ a series of $\mathrm{m}), 0.68(\mathrm{~s}, 9 \mathrm{H}) .{ }^{13} \mathrm{C} \mathrm{NMR}(100$ $\left.\mathrm{MHz}, \mathrm{CDCl}_{3} / \mathrm{CD}_{3} \mathrm{OD}=1: 1\right) \delta 174.61,72.62,67.72,45.98,43.39$, $43.27,43.25$, 41.79, 41.48, 40.71, 40.58, 39.25, 35.88, 35.59, 34.63, 34.57, $34.41,34.32$, 27.97, 26.61, 26.44, 26.24, 22.86, 22.75, 22.10, 16.83, 16.68, 8.11. ESI-HRMS $(\mathrm{m} / z):[\mathrm{M}+\mathrm{Na}]^{+}$calcd for $\mathrm{C}_{73}\left[{ }^{13} \mathrm{C}\right] \mathrm{H}_{119} \mathrm{~N}_{3}\left[{ }^{15} \mathrm{~N}\right]-$ $\mathrm{O}_{10} \mathrm{Na} 1249.8969$, found 1249.8799 .

Membrane Sample Preparation. Three types of lipid membranes were used to reconstitute the oligocholates: 1,2-didodecanoyl-snglycero-3-phosphocholine (DLPC), 1-palmitoyl-2-oleoyl-sn-glycero-3phosphocholine (POPC) 1-palmitoyl-2-oleoyl-sn-glycero-3-phospho(1'-rac-glycerol) (POPG) (10:1 molar ratio), and POPC/POPG/ cholesterol (10:1:2.5 molar ratio). The trimer/lipid molar ratio was 1:7.5 for the POPC/POPG membrane, both with and without cholesterol, and 1:9.2 for the DLPC sample. These values corresponded to the same mass ratio of about 1:4.5 between the oligocholates and the lipids. Phospholipids, cholesterol, CT, and LT were dissolved in chloroform, mixed, and dried under a stream of nitrogen gas to form a film. The mixture was suspended in $\mathrm{pH} 7.5$ Tris buffer $(10 \mathrm{mM}$ Tris base, $1 \mathrm{mM}$ EDTA, $0.1 \mathrm{mM} \mathrm{NaN}_{3}$ ), vortexed, and dialyzed against buffer for one day at room temperature. The dialysis was used to reduce the salt concentration. The suspension was centrifuged at $150000 \mathrm{~g}$ for $4 \mathrm{~h}$ to obtain a homogeneous membrane pellet and allowed to equilibrate to 35 wt $\%$ hydration. The pellet was then packed into a $4 \mathrm{~mm}$ magic-anglespinning (MAS) rotor for solid-state NMR experiments.

Solid-State NMR Experiments. All NMR experiments were conducted at a $9.4 \mathrm{~T}$ Bruker DSX-400 spectrometer operating at a 
Larmor frequency of $400.49 \mathrm{MHz}$ for ${ }^{1} \mathrm{H}$ and $100.72 \mathrm{MHz}$ for ${ }^{13} \mathrm{C}$. Typical radiofrequency pulse lengths were $4-5 \mu$ s for ${ }^{1} \mathrm{H}$ and $5 \mu$ s for ${ }^{13} \mathrm{C} .{ }^{13} \mathrm{C}$ chemical shifts were referenced to the ${ }^{13} \mathrm{CO}$ signal of $\alpha$-Gly at $176.465 \mathrm{ppm}$ on the TMS scale.

${ }^{13} \mathrm{C}-{ }^{1} \mathrm{H}$ dipolar couplings were measured with use of the $2 \mathrm{D}$ dipolarchemical-shift (DIPSHIFT) correlation experiments under $3.5 \mathrm{kHz}$ MAS at $298 \mathrm{~K}^{37,38}{ }^{1} \mathrm{H}$ homonuclear decoupling was achieved by using the MREV-8 sequence with a ${ }^{1} \mathrm{H} 105^{\circ}$ pulse length of $4.0 \mu \mathrm{s} .{ }^{39}$ The $t_{1}$ dimension was fit to give the apparent coupling, which was divided by the theoretical MREV-8 scaling factor of 0.47 to obtain the true dipolar coupling. The order parameter $S_{\mathrm{CH}}$ was calculated as the ratio of true couplings to rigid limit value, $22.7 \mathrm{kHz}$. The model compound formylMLF was used to verify the MREV- 8 scaling factor.

$2 \mathrm{D}{ }^{13} \mathrm{C}$-detected ${ }^{1} \mathrm{H}$ spin diffusion experiments were carried out to determine the depth of insertion and water accessibility of CT and LT. This method has been well-established for measuring the distances of proteins to the center of the lipid bilayer and to water. ${ }^{40}$ The ${ }^{1} \mathrm{H}$ magnetization from mobile lipid chains and water was first selected by using a ${ }^{1} \mathrm{H} \mathrm{T}_{2}$ filter and was then transferred to the rigid oligocholates during a mixing period $\left(t_{\mathrm{m}}\right)$. A ${ }^{1} \mathrm{H} 180^{\circ}$ pulse was applied in the middle of the $T_{2}$ filter to refocus the isotropic chemical shift. Since the intermolecular distances depend on the magnetization transfer rates, semiquantitative distances can be obtained by fitting the ${ }^{1} \mathrm{H}-{ }^{13} \mathrm{C}$ crosspeak buildup as a function of $t_{\mathrm{m}}$. All samples were measured under $5 \mathrm{kHz}$ MAS above the phase-transition temperature of the lipid membrane. The CT samples were measured at $298 \mathrm{~K}$ while the LT sample was measured at $278 \mathrm{~K}$ to immobilize the polymer while still retaining the ${ }^{1} \mathrm{H}$ magnetization of water and lipid chains.

\section{RESULTS AND DISCUSSION}

Figure 2 shows the $1 \mathrm{D}^{13} \mathrm{C}$ cross-polarization (CP) MAS spectra of $\mathrm{CT}$ and LT, where the labeled ${ }^{13} \mathrm{C} \alpha$ signal is well-resolved

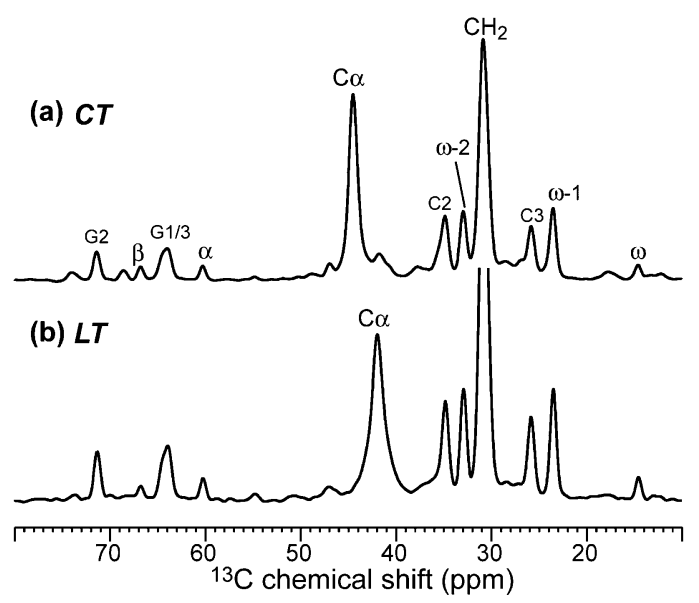

Figure 2. Representative $1 \mathrm{D}^{13} \mathrm{C} \mathrm{CP}-\mathrm{MAS}$ spectra of the cyclic timer (a) and linear trimer $(\mathrm{b})$ in the DLPC bilayer. The spectra were measured at $298 \mathrm{~K}$ under $5 \mathrm{kHz}$ MAS. The single ${ }^{13} \mathrm{C}$ label gives a well-resolved peak at $45 \mathrm{ppm}$ for CT and $42 \mathrm{ppm}$ for LT.

from the natural-abundance lipid ${ }^{13} \mathrm{C}$ signals. The ${ }^{13} \mathrm{C}$ chemical shifts for the CT (45 ppm) and LT (42 ppm) are different due to the different chemical structures: the $\mathrm{C} \alpha$ is connected to two amide groups in CT while sandwiched between an amide and a methyl ester in LT. The well-resolved signal of the ${ }^{13} \mathrm{C}$ label allowed us to probe the dynamics and depth of insertion of the two oligocholates. Although the effect of the oligocholates on the lipid dynamics is not the focus of this work, the lipid ${ }^{13} \mathrm{C}$ signals in the above spectra, as well as the ${ }^{1} \mathrm{H}$ and ${ }^{31} \mathrm{P}$ spectra of the lipids (data not shown), indicate little change of lipid dynamics in the presence of the oligocholates.
Dynamics of CT and LT in Different Membranes. Among the three membranes used, DLPC is the thinnest and has a low phase-transition temperature of $-2{ }^{\circ} \mathrm{C}$. The POPC/POPG membrane is thicker but has a similar phase-transition temperature as DLPC bilayers. The POPC/POPG/cholesterol membrane has the highest membrane viscosity and thickness. The choice of the three lipid systems was the same as in our previous study. ${ }^{21}$ The monounsaturated POPC represents the dominant lipids in the plasma membranes of eukaryotic cells. ${ }^{41}$ POPG was added to increase the colloidal stability of the liposomes in our leakage assays. ${ }^{21}$ Inclusion of cholesterol into the POPC/POPG membrane is known to increase its hydrophobicity and hydrophobic thickness ${ }^{41}$ but, counterintuitively, enhanced the transmembrane movement of glucose induced by 1 and $2 .{ }^{21}$ Since hydrophobic interactions are hypothesized to drive the stacking of the oligocholate macrocycles, DLPC was chosen for its lower hydrophobicity. ${ }^{42}$ The glucose leakage from POPC/POPG liposomes reached 100\% in $30 \mathrm{~min}$ with $>1 \mathrm{~mol} \%$ cyclic trimer 1 in the membrane. ${ }^{21}$ Thus, CT is expected to be well above its critical aggregation concentration in the membrane at [oligocholate $] /[$ lipids $]=1: 7.5$ used for the NMR studies. Since the oligocholates are insoluble in water, we could not add $\mathrm{CT}$ and LT to preformed liposomes at such high oligocholate concentrations. Instead, by premixing the lipids and the oligocholates before film formation, we could ensure that the oligocholates were well-dispersed in the membranes.

To determine the mobility of $\mathrm{CT}$ and $\mathrm{LT}$ in various membranes, we measured the ${ }^{13} \mathrm{C}-{ }^{1} \mathrm{H}$ dipolar couplings using the DIPSHIFT experiment. ${ }^{38}$ These experiments were conducted at $298 \mathrm{~K}$, above the phase-transition temperatures of the membranes. Figures 3 and 4 show the ${ }^{13} \mathrm{C}-{ }^{1} \mathrm{H}$ dipolar dephasing curves of CT and LT, respectively. In all three membranes, CT exhibited much deeper dephasing than LT, indicating larger dipolar couplings. The order parameters were $>0.8$ for $\mathrm{CT}$ and $\sim 0.5$ for LT. Therefore, CT was mostly immobilized in the membranes while LT underwent large-amplitude motions. Notably, the membrane thickness and viscosity had little effect on the order parameters of CT. This is interesting, because both leakage assays and fluorescent studies showed that the stacking of the cholate macrocycles increased in the order of DLPC < POPC/POPG < POPC/POPG/cholesterol. ${ }^{21,22}$ Thus, the different aggregational tendency of $\mathrm{CT}$ in these membranes was insufficient to cause dynamic differences. Because the mobility of CT was inferred from the labeled glycine, it is possible that the slow motion simply results from the rigid, cyclic structure.

The dynamic nature of LT is in agreement with our previous findings. Fluorescent data suggested that the linear trimer had a stronger preference for the membrane surface than the cyclic analogue. ${ }^{32}$ Even though the linear trimer can aggregate intermolecularly at high concentrations and migrate into the hydrophobic core of the membrane, the aggregates seem to be quite unstable and in rapid equilibrium with the surface-bound species, which are expected to be quite mobile. The dynamics of LT observed in the ${ }^{13} \mathrm{C}-{ }^{1} \mathrm{H}$ dipolar coupling data is consistent with its surface binding. As long as the aggregationdeaggregation is fast on the NMR time scale and the aggregated LT represents a small population of all the LT molecules, we would expect relatively fast motion for the linear trimer.

As shown by Figure 4, the LT order parameters increased significantly from DLPC (0.44) to POPC/POPG/cholesterol (0.57). Hence, LT becomes less mobile as the membrane becomes more viscous, thicker, and more hydrophobic. The 
(a) $C T$ in DLPC

(b) $C T$ in POPC/G

(c) $C T$ in POPC/G+Chol
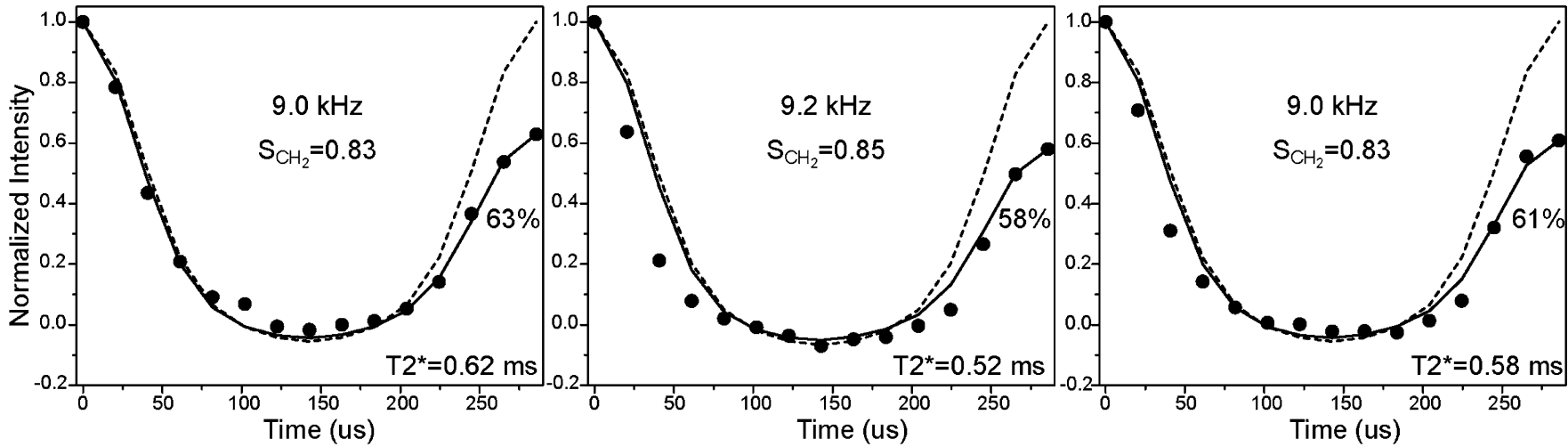

Figure 3. ${ }^{13} \mathrm{C}-{ }^{1} \mathrm{H}$ dipolar couplings of $\mathrm{CT}$ in (a) DLPC, (b) POPC/POPG, and (c) POPC/POPG/cholesterol bilayers to determine CT dynamics in the membrane. All data were measured at $298 \mathrm{~K}$ under $3.5 \mathrm{kHz}$ MAS. The solid and dashed lines were best-fit simulations with and without an empirical $\mathrm{T}_{2}$ decay. The intensity of the last time point relative to the first time point is indicated, along with the apparent $\mathrm{T}_{2}$. All three CT samples showed dipolar order parameter of $\sim 0.84$, indicating small-amplitude motion.

(a) $L T$ in DLPC

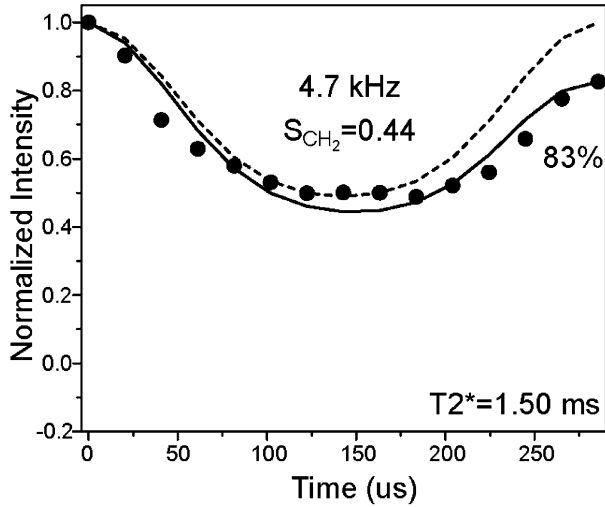

(b) $L T$ in $P O P C / G$

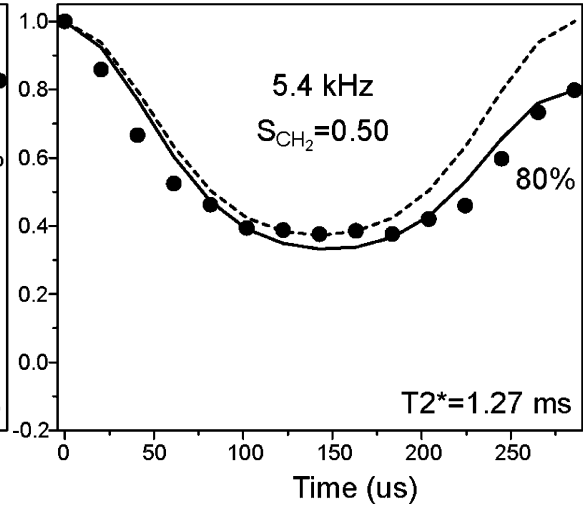

(c) $L T$ in POPC/G+Chol

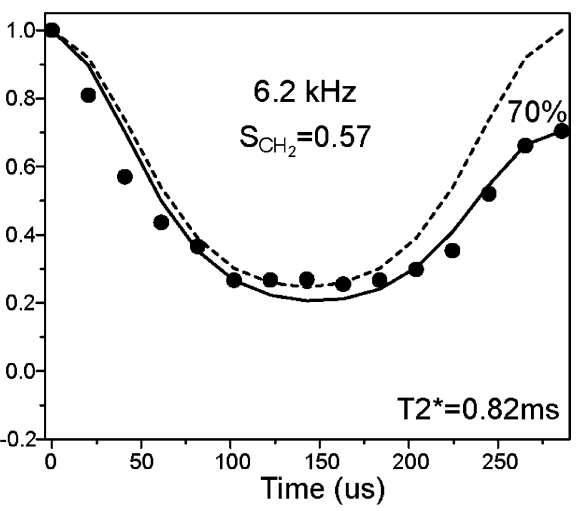

Figure 4. ${ }^{13} \mathrm{C}-{ }^{1} \mathrm{H}$ dipolar couplings of LT in (a) DLPC, (b) POPC/POPG, and (c) POPC/POPG/cholesterol bilayers. Experimental conditions and symbols were the same as in Figure 3. LT had significantly weaker dipolar couplings and smaller order parameter than CT, indicating large-amplitude motion in all three membranes.
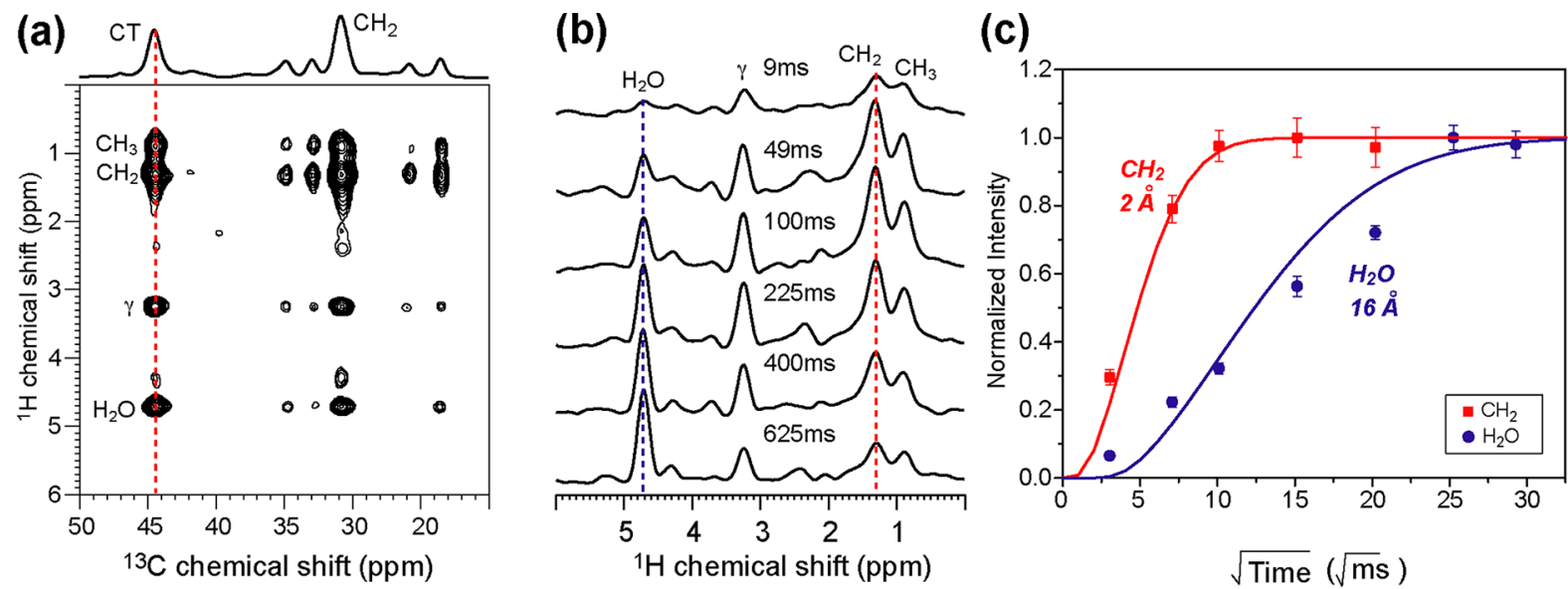

Figure 5. 2D ${ }^{13} \mathrm{C}$-detected ${ }^{1} \mathrm{H}$ spin diffusion of DLPC-bound CT to determine the depth of insertion. (a) Representative $2 \mathrm{D}$ spectrum with $100 \mathrm{~ms}$ mixing time. (b) ${ }^{1} \mathrm{H}$ cross sections of the $\mathrm{C} \alpha$ peak as a function of mixing time. (c) Buildup curves of lipid $\mathrm{CH}_{2}$ (red) and $\mathrm{H}_{2} \mathrm{O}$ (blue) cross peaks. The corresponding peaks are marked in panel b by dashed lines. Best fit was obtained with $2 \AA$ for $\mathrm{CH}_{2}$ and $16 \AA$ for the $\mathrm{H}_{2} \mathrm{O}$ cross peak. Fitting parameters

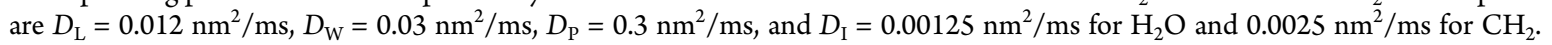

lower mobility may be caused by the reduced mobility of both the surface-bound LT and the intermolecular aggregates located deeper in the membrane in a more viscous environment. Another contribution might come from the membrane-dependent aggregation of the linear trimer. As the hydrophobicity of the membrane increases from DLPC to POPC/POPG and then to 


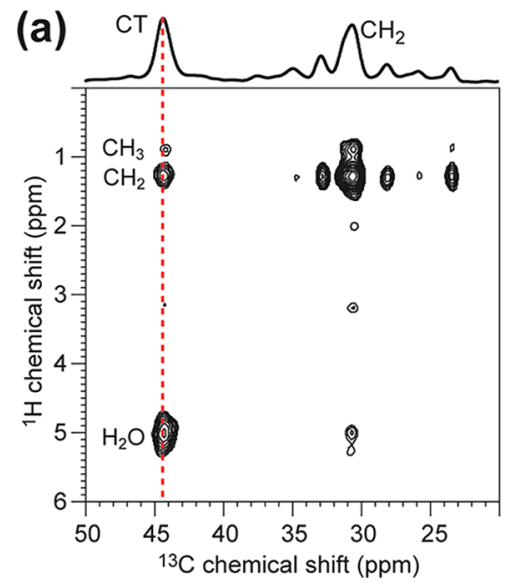

(b)

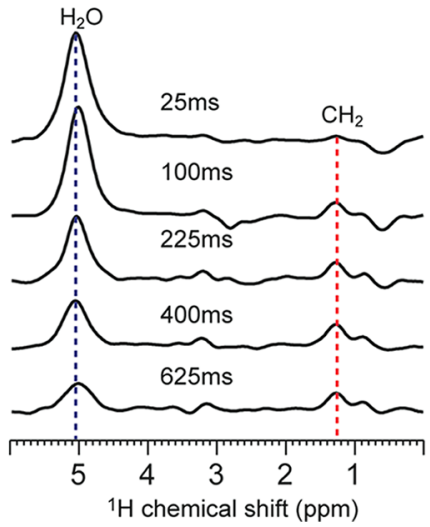

(c)

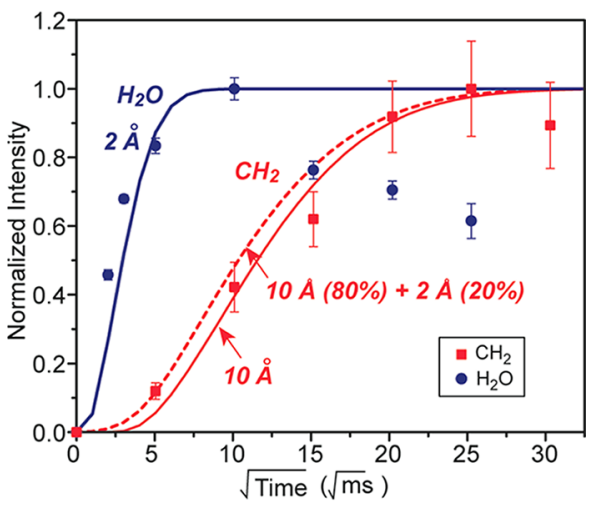

Figure 6. $2 \mathrm{D}{ }^{13} \mathrm{C}$-detected ${ }^{1} \mathrm{H}$ spin diffusion of $\mathrm{CT}$ in the POPC/POPG bilayer. (a) Representative $2 \mathrm{D}$ spectrum with a $625 \mathrm{~ms}$ mixing time. (b) ${ }^{1} \mathrm{H}$ cross sections of the $\mathrm{C} \alpha$ peak as a function of mixing time. (c) Buildup curves of the lipid $\mathrm{CH}_{2}$ (red) and $\mathrm{H}_{2} \mathrm{O}$ (blue) cross peaks. Best fit was obtained with $2 \AA$ for the $\mathrm{H}_{2} \mathrm{O}$ buildup and a predominant distance of $10 \AA$ for the lipid $\mathrm{CH}_{2}$ buildup. Combination of $10 \AA$ ( $\left.80 \%\right)$ and $2 \AA$ (20\%) also has a reasonable fit for experimental data (red dashed line). Diffusion coefficients are $D_{\mathrm{L}}=0.012 \mathrm{~nm}^{2} / \mathrm{ms}, D_{\mathrm{W}}=0.03 \mathrm{~nm}^{2} / \mathrm{ms}, D_{\mathrm{P}}=0.3 \mathrm{~nm} / \mathrm{ms}$, and $D_{\mathrm{I}}=$ $0.0025 \mathrm{~nm}^{2} / \mathrm{ms}$ for $\mathrm{H}_{2} \mathrm{O}$ and $0.00125 \mathrm{~nm}^{2} / \mathrm{ms}$ for $\mathrm{CH}_{2}$.

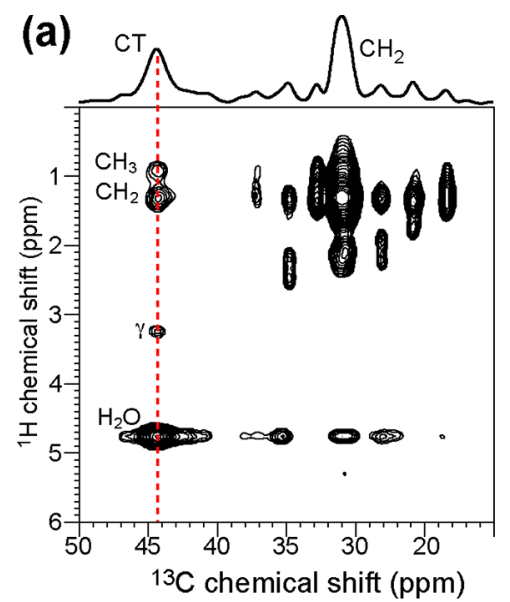

(b)

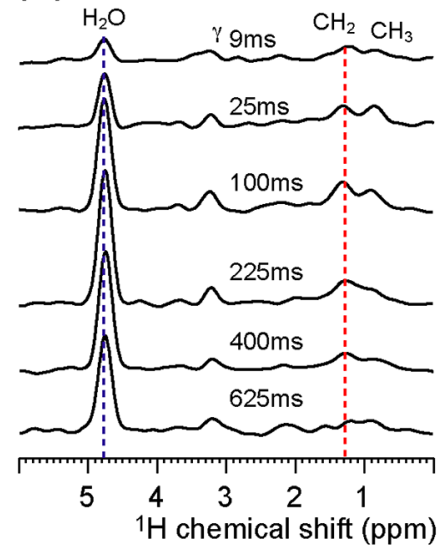

(c)

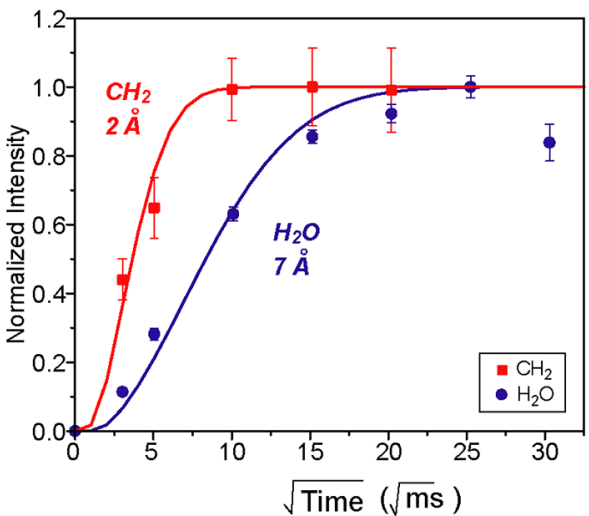

Figure 7. $2 \mathrm{D}^{13} \mathrm{C}$-detected ${ }^{1} \mathrm{H}$ spin diffusion of $\mathrm{CT}$ in the POPC/POPG/cholesterol membrane. (a) Representative $2 \mathrm{D}$ spectrum with a $100 \mathrm{~ms}$ mixing time. (b) ${ }^{1} \mathrm{H}$ cross sections of the CT peak as a function of mixing time. (c) Buildup curves of the lipid $\mathrm{CH}_{2}$ (red) and $\mathrm{H}_{2} \mathrm{O}$ (blue) cross peaks. Best fit was obtained with $2 \AA$ for the $\mathrm{CH}_{2}$ and $7 \AA$ for the $\mathrm{H}_{2} \mathrm{O}$ curve. Diffusion coefficients are $D_{\mathrm{L}}=0.012 \mathrm{~nm}^{2} / \mathrm{ms}, D_{\mathrm{W}}=0.03 \mathrm{~nm}^{2} / \mathrm{ms}, D_{\mathrm{P}}=0.3 \mathrm{~nm}{ }^{2} / \mathrm{ms}, D_{\mathrm{WP}}=$ $0.00125 \mathrm{~nm}^{2} / \mathrm{ms}$, and $D_{\mathrm{LP}}=0.005 \mathrm{~nm}^{2} / \mathrm{ms}$.

POPC/POPG/cholesterol, the hydrogen bonds among the polar groups of the aggregated oligocholates become stronger. These stronger hydrogen bonds are expected not only to enhance the stability of the aggregates but also to slow down the deaggregation process-both factors should decrease the mobility of LT.

Insertion of CT in DLPC Bilayers. To determine the depth of insertion of the oligocholates in the lipid membrane, we carried out the ${ }^{13} \mathrm{C}$-detected ${ }^{1} \mathrm{H}$ spin diffusion experiments at 298 $\mathrm{K}$. For the DLPC-bound CT, significant cross peaks from the lipid $\mathrm{CH}_{2}(1.3 \mathrm{ppm})$ and $\mathrm{CH}_{3}(0.9 \mathrm{ppm})$ protons to $\mathrm{CT}^{13} \mathrm{C}$ were observed already at short mixing times $(9 \mathrm{~ms})$, reaching a plateau by $100 \mathrm{~ms}$ (Figure 5). The buildup curve was best fit to a $2 \AA$ distance, indicating that CT fully inserts into the DLPC bilayer. In comparison, the water cross peak with $\mathrm{CT}$ was very slow to develop, reaching a plateau only at $625 \mathrm{~ms}$. The slow intensity buildup was best fit to a distance of $16 \AA$.

The short, $2 \AA$ average distance of CT to the lipid $\mathrm{CH}_{2}$ in the DLPC membrane is reasonable from the viewpoint of molecular dimension. The hydrophobic thickness of the DLPC bilayer is about $2.0 \mathrm{~nm}^{43}$ The height of the CT is about $0.6-0.7 \mathrm{~nm}$ according to its CPK model. When solubilized in the hydrophobic region of the membrane, the ${ }^{13} \mathrm{C}$ label should be quite close to most carbons on the C-12 chain of DLPC. On the other hand, the $16 \AA$ average distance between $\mathrm{CT}$ and water was much longer than expected. We had envisioned that the highly hydrophilic interior of CT would always carry a pocket of water, regardless of the membrane structure, and thus anticipated a rapid buildup of the water cross peaks. For ion channels in lipid membranes, as long as the channel is hydrated, the channel water and membrane-surface water equilibrate rapidly on the NMR time scale, giving fast intensity buildup for the water-protein cross peaks. ${ }^{44,45}$ One possible explanation for the unusually slow buildup of the water cross peaks is that the CT pore may be dehydrated in the DLPC membrane. Filling the interior of CT with lipid chains, however, does not seem favorable from an energetic point of view. An alternative possibility, which is more consistent with the previous fluorescent data, ${ }^{32}$ is that water molecules may be present in the interior of the macrocycle in the DLPC bilayer but may not form a continuous conduit to the membrane surface. In comparison to a TM channel with rapidly exchanging water molecules with the surface water, the CT 


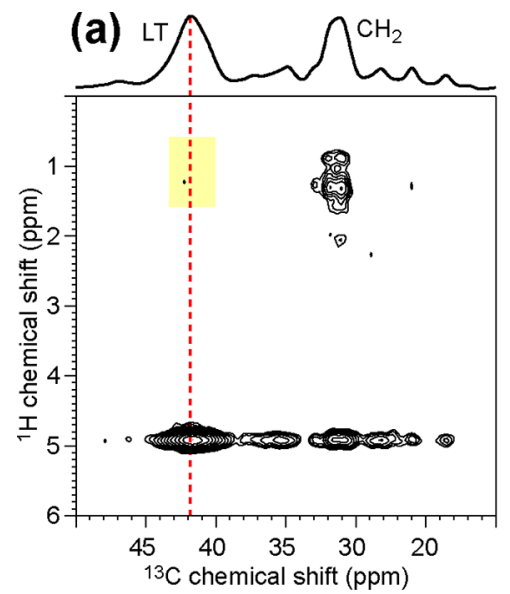

(b)

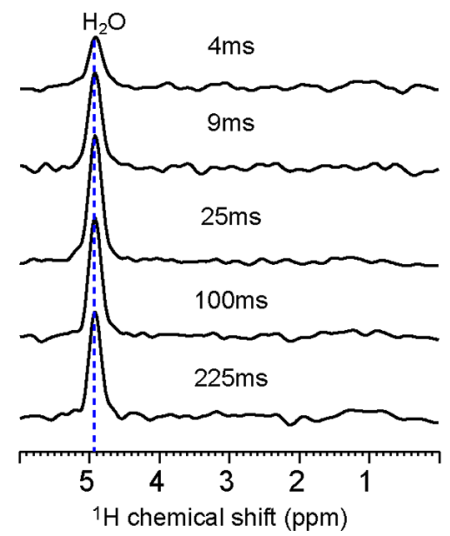

(c)

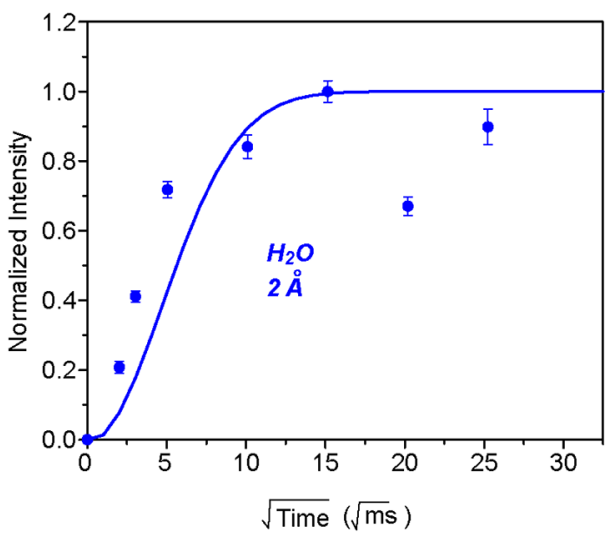

Figure 8. $2 \mathrm{D}{ }^{13} \mathrm{C}$-detected ${ }^{1} \mathrm{H}$ spin diffusion of LT in the POPC/POPG/cholesterol membrane at $278 \mathrm{~K}$ under $5 \mathrm{kHz}$ MAS. (a) Representative $2 \mathrm{D}$ spectrum with a $225 \mathrm{~ms}$ mixing time. The lipid $\mathrm{CH}_{2}$ cross peak is absent (yellow highlight), indicating that LT resides on the membrane surface. (b) ${ }^{1} \mathrm{H}$ cross sections of the LT C $\alpha$ peak as a function of mixing time. (c) The water buildup curve is best fit to $2 \AA$ using $D_{\mathrm{L}}=0.012 \mathrm{~nm}^{2} / \mathrm{ms} D_{\mathrm{W}}=0.03 \mathrm{~nm} / \mathrm{ms}^{2}$, $D_{\mathrm{P}}=0.3 \mathrm{~nm}^{2} / \mathrm{ms}$, and $D_{\mathrm{WP}}=0.0025 \mathrm{~nm}^{2} / \mathrm{ms}$.

molecules in DLPC bilayers under such a circumstance would experience much fewer water molecules in a given period of time, causing water cross peaks to develop more slowly.

Insertion of CT into POPC/POPG Membranes. Interestingly, in the POPC/POPG membrane, the lipid and water cross peaks to CT reversed trends from the DLPC case (Figure 6): the lipid cross peak intensities increased much more slowly, reaching a plateau only at $625 \mathrm{~ms}$, while the water cross peak equilibrated rapidly, by $100 \mathrm{~ms}$. The lipid chain-CT cross peak buildup was best fit to an average distance of $10 \AA$, indicating that the cyclic trimer was shallowly inserted in the POPC/POPG membrane, far from the lipid $\mathrm{CH}_{2}$ groups but with immediate access to water.

The hydrophobic thickness of POPC is about $2.6 \mathrm{~nm} .^{41}$ Thus, if $\mathrm{CT}$ is close to the membrane surface, its height $(0.6-0.7 \mathrm{~nm})$ would not allow it to be in contact with much of the lipid tail. The $10 \AA$ average distance to the lipid $\mathrm{CH}_{2}$ thus supports partial insertion of the CT. Since CT is effective at transporting glucose above $0.5 \mathrm{~mol} \%$ of the POPC/POPG membrane, ${ }^{21}$ we hypothesize that the depth of $10 \AA$ is an average quantity from a small fraction of fully inserted macrocycles and a dominant fraction of surface-bound species. Indeed, simulations show that the experimental data can be equally well fit to a superposition of a $20 \%$ population of a $2-\AA$ distance and an $80 \%$ population of a $10-\AA$ distance (Figure 6 ). Increasing the fraction of the $2-\AA$ component above $20 \%$ induces much faster buildup than observed. Thus, only a small fraction of the macrocycles might be responsible for the glucose transport, while the majority of CT is surface-bound and inactive. In this scenario, the high water cross peak in this membrane should result predominantly from the surface-bound CT.

Insertion of CT and LT into POPC/POPG/Cholesterol Membranes. CT displayed the most interesting behavior in the POPC/POPG/cholesterol membrane (Figure 7). The lipidchain cross peaks rose similarly rapidly as in the DLPC bilayer, with an average distance of $2 \AA$ to the lipid $\mathrm{CH}_{2}$. Hence, as the hydrophobic thickness of POPC membranes increased from 2.6 to $3.0 \mathrm{~nm},{ }^{41}$ the macrocycle actually became closer to the lipid tails. This result provides the strongest evidence for the TM stacking model for the cyclic oligocholates. As supported by the glucose leakage assays ${ }^{21}$ and fluorescence studies, ${ }^{31,32}$ by increasing the hydrophobicity of the membrane, cholesterol affords a stronger driving force to the pore formation (Figure 1).
The addition of cholesterol thus favors stacking, transferring more of the surface-bound CT to the hydrophobic core of the membrane.

Another interesting observation is the water cross peak buildup: it is intermediate between the DLPC and POPC/POPG cases and fits to a distance of $7 \AA$. We believe this result supports our explanation for the seemingly "dehydrated" CT in the DLPC membranes. When solubilized in a thicker, more hydrophobic membrane, CT should have more difficulty contacting the surface water molecules. Yet, despite its deep penetration into the membrane (evident from its $2 \AA$ average distance to the lipid $\mathrm{CH}_{2}$ ), $\mathrm{CT}$ showed a shorter distance to water in the thicker POPC/POPG/cholesterol membrane than in the thinner DLPC membrane. These unusual results are readily explained by our TM stacking model (Figure 1): the more hydrophobic the membrane, the better can the CT molecules stack into the TM pore. Once a nanopore is formed to span the entire thickness of the bilayer, the water molecules inside the pore can exchange with those on the surface readily, giving rise to faster buildup curves than those observed for the DLPC membrane. ${ }^{46}$

For comparison, we also measured the depth of insertion of LT in the POPC/POPG/cholesterol membrane. Since LT undergoes significant motion at ambient temperature, its ${ }^{13} \mathrm{C}$ signal cannot be distinguished from the lipid signals with the ${ }^{1} \mathrm{H}$ $\mathrm{T}_{2}$ filter. We, therefore, carried out the spin diffusion experiment at a lower temperature, $278 \mathrm{~K}$, which permitted the complete suppression of the ${ }^{1} \mathrm{H}$ magnetization of LT while maintaining the ${ }^{1} \mathrm{H}$ magnetization of lipids and water. Importantly, both lipids and water remain in the fluid phase at this temperature. Figure 8 shows a strong cross peak between water and LT $\mathrm{C} \alpha$, which reached equilibrium rapidly, indicating that LT was in close contact with the aqueous environment. Meanwhile, no lipid cross peaks were identified until $625 \mathrm{~ms}$, suggesting that the linear trimer cannot move easily into the hydrophobic core of the membrane.

\section{CONCLUSIONS}

The above ${ }^{1} \mathrm{H}$ spin diffusion NMR data depict a striking contrast in the behaviors of CT and LT in phospholipid bilayers. CT can either insert into a membrane or stay near the surface, depending on the membrane thickness and the presence of cholesterol. In contrast, LT strongly prefers the membrane surface, in close 
contact with the membrane-surface water. The surface preference of LT explains the poor transport activity of the linear tricholate. ${ }^{21,22,47}{ }^{13} \mathrm{C}-{ }^{1} \mathrm{H}$ dipolar couplings show that LT is much more dynamic than CT. It is known that rigid oligocholates (i.e., those without any additional tethering units between the cholates) can only form loose, unstable aggregates in nonpolar environments. ${ }^{47,48}$ Thus, even if LT aggregates in the membrane, these aggregates must represent a minor fraction of all the LT molecules and/or be in rapid equilibrium with the highly dynamic, surface-bound species.

This study demonstrates the power of solid-state NMR spectroscopy in characterizing self-assembled structures in phospholipid bilayers on a molecular level. ${ }^{49}$ Even though solid-state NMR has been employed extensively to study membrane peptides and proteins, the method is rarely used to characterize synthetic nanopores. Synthetic pore-forming compounds are structural and functional mimics of biological pore-forming proteins but the lipid membrane represents an extremely challenging medium for mechanistic studies of molecular self-assembly. Fluorescence spectroscopy is popular in membrane chemistry because of its high sensitivity. Nevertheless, bulky fluorescent labels are required, which may affect the self-assembly and typically afford low-resolution structural information at the end. Solid-state NMR spectroscopy, on the other hand, utilizes stable isotopes with minimal perturbation to the parent structure and, most importantly, can reveal atomicscale information as shown in this study.

\section{AUTHOR INFORMATION}

\section{Corresponding Author}

*E-mail: zhaoy@iastate.edu and mhong@iastate.edu.

\section{Notes}

The authors declare no competing financial interest.

\section{ACKNOWLEDGMENTS}

We thank NSF (DMR-1005515) for supporting the research.

\section{REFERENCES}

(1) Hopkins, A. L.; Groom, C. R. The druggable genome. Nat. Rev. Drug Discovery 2002, 1, 727-730.

(2) Lundstrom, K. Latest development in drug discovery on g proteincoupled receptors. Curr. Protein Pept. Sci. 2006, 7, 465-470.

(3) Lee, A. G. Biomembranes: A multi-volume treatise; JAI Press: Greenwich, CT, 1995.

(4) Menestrina, G.; Dalla Serra, M.; Lazarovici, P. Pore-forming peptides and protein toxins; Taylor \& Francis: London, UK, 2003.

(5) Tamm, L. K. Protein-lipid interactions: From membrane domains to cellular networks; Wiley-VCH: Weinheim, Germany, 2005.

(6) Matile, S.; Som, A.; Sorde, N. Recent synthetic ion channels and pores. Tetrahedron 2004, 60, 6405-6435.

(7) Sisson, A. L.; Shah, M. R.; Bhosale, S.; Matile, S. Synthetic ion channels and pores (2004-2005). Chem. Soc. Rev. 2006, 35, 12691286.

(8) Stein, W. D. Carriers and pumps: An introduction to membrane transport; Academic Press: San Diego, CA, 1990.

(9) Gokel, G. W.; Carasel, I. A. Biologically active, synthetic ion transporters. Chem. Soc. Rev. 2007, 36, 378-389.

(10) Fyles, T. M. Synthetic ion channels in bilayer membranes. Chem. Soc. Rev. 2007, 36, 335-347.

(11) McNally, B. A.; Leevy, W. M.; Smith, B. D. Recent advances in synthetic membrane transporters. Supramol. Chem. 2007, 19, 29-37.

(12) Davis, J. T.; Okunola, O.; Quesada, R. Recent advances in the transmembrane transport of anions. Chem. Soc. Rev. 2010, 39, 38433862 .
(13) Litvinchuk, S.; Sorde, N.; Matile, S. Sugar sensing with synthetic multifunctional pores. J. Am. Chem. Soc. 2005, 127, 9316-9317.

(14) Kasianowicz, J. J.; Brandin, E.; Branton, D.; Deamer, D. W. Characterization of individual polynucleotide molecules using a membrane channel. Proc. Natl. Acad. Sci. U.S.A. 1996, 93, 13770-13773.

(15) Akeson, M.; Branton, D.; Kasianowicz, J. J.; Brandin, E.; Deamer, D. W. Microsecond time-scale discrimination among polycytidylic acid, polyadenylic acid, and polyuridylic acid as homopolymers or as segments within single RNA molecules. Biophys. J. 1999, 77, 32273233.

(16) Meller, A.; Nivon, L.; Brandin, E.; Golovchenko, J.; Branton, D. Rapid nanopore discrimination between single polynucleotide molecules. Proc. Natl. Acad. Sci. U.S.A. 2000, 97, 1079-1084.

(17) Vercoutere, W.; Winters-Hilt, S.; Olsen, H.; Deamer, D.; Haussler, D.; Akeson, M. Rapid discrimination among individual DNA hairpin molecules at single-nucleotide resolution using an ion channel. Nat. Biotechnol. 2001, 19, 248-252.

(18) Howorka, S.; Cheley, S.; Bayley, H. Sequence-specific detection of individual DNA strands using engineered nanopores. Nat. Biotechnol. 2001, 19, 636-639.

(19) Clarke, J.; Wu, H. C.; Jayasinghe, L.; Patel, A.; Reid, S.; Bayley, H. Continuous base identification for single-molecule nanopore DNA sequencing. Nat. Biotechnol. 2009, 4, 265-270.

(20) Sakai, N.; Sorde, N.; Matile, S. Synthetic catalytic pores. J. Am. Chem. Soc. 2003, 125, 7776-7777.

(21) Cho, H.; Widanapathirana, L.; Zhao, Y. Water-templated transmembrane nanopores from shape-persistent oligocholate macrocycles. J. Am. Chem. Soc. 2011, 133, 141-147.

(22) Cho, H.; Zhao, Y. Translocation of hydrophilic molecules across lipid bilayers by salt-bridged oligocholates. Langmuir 2011, 27, 49364944.

(23) Granja, J. R.; Ghadiri, M. R. Channel-mediated transport of glucose across lipid bilayers. J. Am. Chem. Soc. 1994, 116, 10785-10786.

(24) Sakai, N.; Mareda, J.; Matile, S. Rigid-rod molecules in biomembrane models: From hydrogen-bonded chains to synthetic multifunctional pores. Acc. Chem. Res. 2005, 38, 79-87.

(25) Das, G.; Talukdar, P.; Matile, S. Fluorometric detection of enzyme activity with synthetic supramolecular pores. Science 2002, 298, 16001602.

(26) Helsel, A. J.; Brown, A. L.; Yamato, K.; Feng, W.; Yuan, L. H.; Clements, A. J.; Harding, S. V.; Szabo, G.; Shao, Z. F.; Gong, B. Highly conducting transmembrane pores formed by aromatic oligoamide macrocycles. J. Am. Chem. Soc. 2008, 130, 15784-15785.

(27) Ma, L.; Melegari, M.; Colombini, M.; Davis, J. T. Large and stable transmembrane pores from guanosine-bile acid conjugates. J. Am. Chem. Soc. 2008, 130, 2938-2939.

(28) Satake, A.; Yamamura, M.; Oda, M.; Kobuke, Y. Transmembrane nanopores from porphyrin supramolecules. J. Am. Chem. Soc. 2008, 130, 6314-6315.

(29) Fyles, T. M.; Tong, C. C. Long-lived and highly conducting ion channels formed by lipophilic ethylenediamine palladium(II) complexes. New J. Chem. 2007, 31, 655-661.

(30) Dunitz, J. D. The entropic cost of bound water in crystals and biomolecules. Science 1994, 264, 670.

(31) Widanapathirana, L.; Zhao, Y. Aromatically functionalized cyclic tricholate macrocycles: Aggregation, transmembrane pore formation, flexibility, and cooperativity. J. Org. Chem. 2012, 77, 4679-4687.

(32) Widanapathirana, L.; Zhao, Y. Effects of amphiphile topology on the aggregation of oligocholates in lipid membranes: Macrocyclic versus linear amphiphiles. Langmuir 2012, 28, 8165-8173.

(33) Hong, M.; Zhang, Y.; Hu, F. Membrane protein structure and dynamics from NMR spectroscopy. Annu. Rev. Phys. Chem. 2012, 63, 124.

(34) Luca, S.; Heise, H.; Baldus, M. High-resolution solid-state NMR applied to polypeptides and membrane proteins. Acc. Chem. Res. 2003, $36,858-865$.

(35) Huster, D.; Yao, X. L.; Hong, M. Membrane protein topology probed by ${ }^{1} \mathrm{H}$ spin diffusion from lipids using solid-state NMR spectroscopy. J. Am. Chem. Soc. 2002, 124, 874-883. 
(36) Kumashiro, K. K.; Schmidt-Rohr, K.; Murphy, O. J.; Ouellette, K. L.; Cramer, W. A.; Thompson, L. K. A novel tool for probing membrane protein structure: Solid-state NMR with proton spin diffusion and $\mathrm{x}$ nucleus detection. J. Am. Chem. Soc. 1998, 120, 5043-5051.

(37) Hong, M.; Gross, J. D.; Rienstra, C. M.; Griffin, R. G.; Kumashiro, K. K.; Schmidt-Rohr, K. Coupling amplification in 2D MAS NMR and its application to torsion angle determination in peptides. J. Magn. Reson. 1997, 129, 85-92.

(38) Munowitz, M. G.; Griffin, R. G.; Bodenhausen, G.; Huang, T. H. Two-dimensional rotational spin-echo NMR in solids: Correlation of chemical shift and dipolar interactions. J. Am. Chem. Soc. 1981, 103, $2529-2533$.

(39) Rhim, W. K.; Elleman, D. D.; Vaughan, R. W. Analysis of multiplepulse NMR in solids. J. Chem. Phys. 1973, 59, 3740-3749.

(40) Mani, R.; Cady, S. D.; Tang, M.; Waring, A. J.; Lehrer, R. I.; Hong, $\mathrm{M}$. Membrane-dependent oligomeric structure and pore formation of a $\beta$-hairpin antimicrobial peptide in lipid bilayers from solid-state NMR. Proc. Natl. Acad. Sci. U.S.A. 2006, 103, 16242-16247.

(41) Nezil, F. A.; Bloom, M. Combined influence of cholesterol and synthetic amphiphillic peptides upon bilayer thickness in model membranes. Biophys. J. 1992, 61, 1176-1183.

(42) Lande, M. B.; Donovan, J. M.; Zeidel, M. L. The relationship between membrane fluidity and permeabilities to water, solutes, ammonia, and protons. J. Gen. Physiol. 1995, 106, 67-84.

(43) Lewis, B. A.; Engelman, D. M. Lipid bilayer thickness varies linearly with acyl chain length in fluid phosphatidylcholine vesicles. J. Mol. Biol. 1983, 166, 211-217.

(44) Smondyrev, A. M.; Voth, G. A. Molecular dynamics simulation of proton transport through the influenza A virus M2 channel. Biophys. J. 2002, 83, 1987-1996.

(45) Luo, W.; Hong, M. Conformational changes of an ion channel membrane protein detected through water-protein interactions using solid-state NMR spectroscopy. J. Am. Chem. Soc. 2010, 132, 2378-2384.

(46) The slower water cross peak buildup for CT in DLPC than in POPC/POPG seems to indicate that the macrocycle was deeper into the thinner membrane, although no continuous water channel was formed. This picture is reasonable because deep penetration of the macrocycle into the more hydrophobic POPC/POPG membrane in the nonaggregated form is unfavorable, as such movement increases the (unfavorable) contact between the entrapped water molecules and the lipid hydrocarbon.

(47) Zhang, S. Y.; Zhao, Y. Flexible oligocholate foldamers as membrane transporters and their guest-dependent transport mechanism. Org. Biomol. Chem. 2012, 10, 260-266.

(48) Zhao, Y. Spacer-dependent folding and aggregation of oligocholates in sds micelles. J. Org. Chem. 2009, 74, 7470-7480.

(49) The present solid-state NMR experiments used molecular dynamics to probe the aggregation of the oligocholates in the membrane. In principle, direct measurement of the aggregates is also possible with solid-state NMR, e.g., by incorporating ${ }^{19} \mathrm{~F}$ labels and measuring intermolecular ${ }^{19} \mathrm{~F}-{ }^{19} \mathrm{~F}$ distances. For reference, see: Luo, W.; Hong, M. Determination of the Oligomeric Number and Intermolecular Distances of Membrane Protein Assemblies by Anisotropic ${ }^{1} \mathrm{H}$-Driven Spin Diffusion NMR. J. Am. Chem. Soc. 2006, 128, 7242-7251. 